\title{
O pesquisador e a produção científica
}

Fernanda Dias Droescher

Mestre em Ciência da Informação pela
Universidade Federal de Santa Catarina
Bibliotecária da Companhia de Habitação do
Estado de Santa Catarina (COHAB/SC)

Edna Lucia da Silva

\begin{abstract}
Doutora em Ciência da Informação pela Universidade Federal do Rio de Janeiro (IBICT) Professora do Departamento e Programa de Ciência da Informação da Universidade Federal de Santa Catarina
\end{abstract}

Reflexão sobre aspectos que mobilizam o pesquisador na produção científica e como essa produção tem sido afetada e avaliada na sociedade contemporânea. Para tanto, aborda o pesquisador, seus objetivos e motivações, a Internet e a produção científica e medidas de impacto da produção científica.

Palavras-chave: Comunicação científica; Pesquisador; Produção científica; Internet; Medidas de Impacto.

\section{Researchers and scientific production}

This paper looks at aspects that aid researchers in scientific production and at how this production is affected and assessed within contemporary society. To this end, it describes researchers, their aims and motivations, the Internet and scientific production and measures of impact for scientific production.

Keywords: Scientific communication; Researchers; Scientific production; Internet; Measures of Impact.

Recebido em14.10.2013 Aceito em 04.12.2013

\section{Introdução}

A principal finalidade da ciência é perceber e entender os fenômenos da natureza. Nesse sentido, é considerada instrumento indispensável na 
incessante busca de respostas que satisfaçam as mais diversas necessidades de toda a sociedade.

Merton (1979), representante da sociologia clássica da ciência, ressaltava que a meta institucional da ciência é a ampliação dos conhecimentos certificados, reconhecidos. Com o intuito de auxiliar a conquista dessa meta, esse autor apresentou os quatro princípios institucionais que estabelecem o ethos científico, ou seja, o comportamento padrão que deveria ser adotado pelos cientistas, que são: universalismo, referindo-se que as origens do saber científico não devem depender de características sociais ou pessoais; comunismo (ou compartilhamento) definindo que a ciência é resultado da colaboração social e, por isso, está destinada à comunidade. Os resultados da pesquisa não pertencem exclusivamente ao cientista, mas à sociedade como um todo; desinteresse (ou desapego material), que não deve ser confundido com altruísmo, significa que a prática da ciência deve orientar-se ao engrandecimento dela própria, e não do próprio autor; e ceticismo organizado, firmando que existe uma verificação permanente do conhecimento científico, buscando erros, incoerências e fragilidades.

Percebe-se que todas essas características levam à ampla divulgação e certificação da ciência, de modo a alcançar o maior número possível de leitores e pesquisadores e, assim, cumprir seus objetivos iniciais.

A importância das publicações foi ressaltada por sociólogos pertencentes a um movimento de renovação da sociologia da ciência, que, então, passou a ser denominada de estudos sociais da ciência. Como exemplo recente dessa nova abordagem, podemos citar Latour e Woolgar (1997, p. 42), que compreende a construção do conhecimento científico como um processo para produzir inscrições (documentos) e fazer circular essas inscrições, para os autores, os cientistas pertencem a uma "estranha tribo que passa a maior parte de seu tempo codificando, marcando, lendo e escrevendo", assim são profissionais que precisam "saber escrever, persuadir, discutir". Por outro lado, "os artigos inscritos por outros autores constituem a literatura externa que alimenta - além das inscrições que saem do próprio laboratório - o processo de criação de novos artigos".

O registro da ciência é essencial à conservação e preservação de resultados, observações, cálculos, teorias, etc., possibilitando, assim, a crítica, aceitação ou não e aperfeiçoamentos posteriores. Entretanto, a comunicação desses registros é ação ainda mais importante, condição pela qual se possibilita o alcance público, permitindo, assim, a apropriação desses por outros indivíduos e, consequentemente, a geração de mais conhecimentos.

Ziman (1981, p. 105) já ressaltava tais aspectos quando afirmou que ciência é conhecimento público, no qual cada pesquisador "vai construindo sua parte por cima do trabalho realizado pelos nossos predecessores, numa colaboração competitiva com a dos nossos contemporâneos". De fato, a ciência vai muito além do conhecimento 
pessoal, constituindo-se de tudo aquilo que pode ser transmitido, comunicado de uma pessoa a outra (ZIMAN, 1996).

Nesse sentido, a comunicação é atividade imprescindível ao progresso da ciência. Meadows (1999, p. vii) ressaltou que a comunicação é o coração da ciência, pois coloca em movimento tudo que é vital para a pesquisa, isto é, legitimação e reconhecimento, que irão garantir apoio e recursos financeiros aos pesquisadores. Para o autor, de "qualquer que seja o ângulo pelo qual a examinemos, a comunicação eficiente e eficaz constitui parte essencial do processo de investigação científica".

A comunicação é primordial ao avanço científico, esse fato é consenso, visto que é por meio dela que se torna possível a troca de informações e ideias entre indivíduos para retroalimentação do processo científico. Figueiredo (1992) sintetizou as várias finalidades da comunicação cientifica desta forma: encorajar o pensamento e a ação, por inserção ou interação com ideias de outras pessoas, conhecimento, experiência e realizações; promover o conhecimento contínuo do que outras pessoas estão fazendo, a fim de permitir que indivíduos ou grupos possam saber de desenvolvimentos em seus campos especializados, bem como em outras áreas; diminuir a probabilidade de duplicação de trabalho, evitando perda de tempo e esforço; prover conhecimento básico e introdutório para pesquisas em áreas não familiares; e prover dados específicos necessários para trabalhos em execução.

Além disso, em relação à afirmação das competências de um pesquisador, a comunicação científica também exerce grande influência. Em parte, porque todo cientista visa à consensualidade, ele deseja que o seu trabalho seja conhecido por seus pares e que eles se convençam do seu ponto de vista. A troca de conhecimentos e informações entre cientistas tem como principais objetivos providenciar respostas para questões específicas, ajudar os cientistas a se manterem atualizados quanto a novos descobrimentos, auxiliar pesquisadores a encontrarem informações a respeito de um novo campo científico, além de mostrar as principais tendências em seu campo e dar importância ao seu próprio trabalho.

Para Oliveira e Noronha (2005), a comunicação e a informação exercem um papel fundamental, uma vez que, além de possibilitarem a cooperação e integração entre os pesquisadores, colaboram para a certificação das pesquisas, confirmação das competências e a firmação da credibilidade e aceitação do pesquisador na comunidade científica.

Neste artigo, procuramos fazer uma reflexão baseada em revisão de literatura sobre aspectos que mobilizam o pesquisador na produção científica e como essa produção tem sido afetada e avaliada na sociedade contemporânea.

\section{0 pesquisador, seus objetivos e motivações}

A ciência é um processo altamente dinâmico, em que as descobertas ocorrem ininterruptamente, sempre surgindo novos resultados e novas pesquisas, por isso, seus resultados são quase sempre provisórios e 
transitórios. Dessa forma, a ciência configura-se como um sistema contínuo de investigação, que conta com a participação dinâmica dos pesquisadores, os quais, em parte com 0 uso de conhecimentos acumulados, conseguem produzir e dar continuidade a esse ciclo. Portanto, os cientistas, como produtores de ciência, devem registrar todos os seus esforços, os quais possivelmente irão gerar novos conhecimentos. Esses registros, por sua vez, são submetidos a análises criteriosas da comunidade científica, a qual irá aceitar ou rejeitar essas novas ideias. Logo, o avanço da ciência acontece na medida em que as ideias dos cientistas despertam $o$ interesse de seus pares e por eles são referendadas. A comunidade científica, constituída por seus pares, é quem julga a validade das questões colocadas, quem recompensa os cientistas que têm sucesso e reprime (descrédito de suas publicações, não divulgação dos trabalhos) os que, de alguma forma, infringem as normas e as hierarquias (DEUS, 1979, p. 17).

A pressão para a ampla divulgação dos resultados é reforçada pelos objetivos institucionais de ampliar os limites do saber e, também, pelo estímulo à notoriedade, a qual está intimamente ligada à publicidade. De acordo com Hagstrom (1979, p. 87), "a organização da ciência consiste numa troca de informações por reconhecimento social". O compartilhamento da riqueza científica, além de ser fundamental ao reconhecimento do talento do pesquisador, é considerado como uma obrigação moral, de modo a condenar a ocultação das descobertas científicas. Todo esse pensamento é proveniente do entendimento de que o avanço científico depende da colaboração entre as gerações passadas e presentes, pois um novo conhecimento é sempre oriundo de conhecimentos anteriores (MERTON, 1979).

De acordo com Bourdieu (1983), o campo científico é o lugar das disputas concorrenciais, no qual o objetivo principal é a conquista da autoridade cientifica, ou seja, da capacidade técnica e poder social, também conhecido por competência científica. Sendo assim, é possível afirmar que o campo científico origina diversas formas de interesses. Considerando que as práticas científicas, além de se importarem com o avanço da ciência, também se voltam para o ganho de autoridade científica (prestígio, reconhecimento, celebridade etc.), comumente conhecido por interesse; é possível afirmar que o que move as atividades científicas tem sempre mais de um tipo de intenção, bem como as estratégias utilizadas para garantir a satisfação desse interesse. Todavia, é inútil tentar separar as motivações científicas das sociais, as duas devem caminhar juntas, posto que o que é importante para um determinado pesquisador deve o ser também para os outros.

Meadows (1999) realizou um estudo, objetivando verificar o que leva as pessoas a pesquisarem. Observou que a maioria dos entrevistados pesquisa incentivado pelo desejo de crescer intelectualmente. As outras respostas que mais apareceram, em sequência, foram: (a) o desejo de contribuir para a ciência; (b) o interesse intrínseco na área; (c) uma forma de ingressar na carreira acadêmica; (d) possibilidade de melhor remuneração; e (e) desejo de ser útil à comunidade. 
Na mesma linha de pensamento, Le Coadic (1996) aponta dois tipos de motivações presentes nos cientistas. O primeiro é proveniente da própria natureza científica, o amor à ciência; e é representado pela consciência profissional enquanto pesquisador, pelo anseio de provocar debates nos quais coloca suas ideias à prova, pela preocupação sincera com o avanço da ciência e pela possibilidade de colaborar com o processo de decisão. O outro tipo de motivação se refere aos anseios pessoais, tais como o crescimento profissional, a possibilidade de reconhecimento e sucesso, bem como a pressão acadêmica e institucional.

O que se observa é que, independentemente do tipo de motivação, se é pessoal ou científica, o pesquisador leva em conta que o que é verdadeiramente importante e interessante é o que tem chances de assim ser percebido pelos outros. Isso, por sua vez, é o que vai fazer aparecer o autor daquilo que é importante e interessante na percepção dos demais. Dessa forma, os pesquisadores tendem a se concentrar nos problemas considerados como os mais importantes, haja vista que uma contribuição relativa a essas questões gera maior lucro simbólico, segundo Bourdieu (1983). Conforme já constatado por Hagstrom (1979), o desejo de ser reconhecido não só faz com que o cientista comunique as suas pesquisas como também influencia na escolha dos problemas e métodos empregados. A tendência é que o cientista dê preferência às questões cuja resolução possa gerar maior reconhecimento. Da mesma forma, a propensão é que ele opte por utilizar, na tentativa de solucionar a questão proposta, os métodos que colaborem para que seu trabalho seja aceito por seus colegas. Dessa maneira, para que despertem interesse e sejam valorizados, os cientistas devem trazer algum proveito à coletividade; assim, um dos fatores que mais influenciam a credibilidade e relevância do cientista é a contribuição social (PETROIANU, 2002).

Nesse sentido, a autoridade científica, considerada como uma espécie de capital social, encontra o essencial de suas características no fato de que os produtores de conhecimento só esperam o reconhecimento do valor daquilo que produzem (reputação, prestígio, autoridade, competência, etc.) quando essa gratulação é proveniente de outros produtores de conhecimento, os quais, sendo também seus concorrentes, são os menos propensos a reconhecê-lo sem análise ou discussão (BOURDIEU, 1983). Sendo assim, o reconhecimento ocorre, sobretudo, por meio da análise de seus pares. Merton (1979) já havia alertado que as atividades dos pesquisadores estão sujeitas a um rigoroso julgamento, talvez o maior dentre os mais variados campos de atividade.

Compreende-se, então, que o objetivo dos cientistas, como integrantes do campo científico, é buscar aceitação para o que produziram bem como afirmar a sua própria autoridade no papel de produtor científico. Para tanto, é preciso que os cientistas saibam escolher os problemas, as questões que interessem não só a eles, mas aos seus pares e encontrem, para esse dado problema, a definição ou solução mais adequada. De acordo com Bourdieu (1983, p. 128), a melhor solução a ser encontrada pelo cientista será aquela que lhe permita "ocupar legitimamente a posição dominante e a que assegure, aos talentos 
científicos de que ele é detentor a título pessoal ou institucional, a mais alta posição na hierarquia dos valores científicos".

Outro ponto importante para o pesquisador é a sua reputação junto aos seus pares. Além de ser indispensável à conquista de fundos para pesquisa, bolsas, convites, prêmios e outras distinções; é o reconhecimento pelos pares que garante o reconhecimento do cientista. 0 reconhecimento, por sua vez, é a soma do valor distintivo de tudo aquilo que produziu e de sua originalidade. A originalidade é conquistada por aquele que foi o primeiro a realizar ou, ao menos, a tornar conhecida uma determinada descoberta. Já o valor distintivo está relacionado ao conceito de visibilidade, em que "acumular capital é fazer um 'nome', um nome próprio, um nome conhecido e reconhecido, marca que distingue imediatamente seu portador, arrancando-o como forma visível do fundo indiferenciado, despercebido, obscuro, no qual se perde o homem comum". (BOURDIEU, 1983, p. 132).

Merton (1979) já havia postulado que, considerando a influência da gratidão e estima no seio acadêmico como a único direito do autor sobre aquilo que ele produz, o empenho pela prioridade científica, a originalidade, é absolutamente compreensível.

Nesse contexto de disputa pelo reconhecimento científico, Bourdieu (1983) identifica dois atores: os dominantes, ocupando os postos mais elevados na estrutura de distribuição do capital científico; e os novatos, ou dominados. Bourdieu (1983) defende que cada um desses grupos adota estratégias diferentes. Os dominantes utilizam as estratégias de conservação, com o objetivo de preservar a ordem científica com a qual compactuam para, dessa forma, manterem-se em seus postos. Essa estratégia conta com a cooperação das academias e revistas sociais, as quais se empenham, com o auxílio de critérios dominantes, em consagrar produções. Dessa forma, censuram todas as produções que não estão de acordo com seus critérios, rejeitando-as ou simplesmente desencorajando os trabalhos que contrariam as definições por elas impostas. Em contrapartida, os novatos podem adotar as estratégias de sucessão ou as estratégias de subversão. A primeira estratégia se aproveita dos lucros prometidos àqueles que, apesar de seguirem os padrões da excelência científica, tiveram sua carreira interrompida. Nesse caso, basta que se criem inovações, dentro dos limites autorizados, que possibilitem continuidade a essa linha de pensamento. Já no caso das estratégias de subversão, Bourdieu (1983) lembra que os investimentos são mais arriscados e elevados, uma vez que exige uma completa redefinição do que até então era tido como dominante. Bourdieu (1983, p. 139), ao discorrer sobre as estratégias de subversão, afirma que os cientistas que dela se utilizam e realizam a acumulação inicial por intermédio de ruptura com "o crédito de que se beneficiavam os antigos dominantes, sem conceder-Ihes a contrapartida do reconhecimento que lhes oferecem aqueles que aceitam se inserir na continuidade de uma linhagem".

Nesse sentido, o cientista, à medida que se dispõe a produzir respostas a questões de interesse não só dele, mas que também sejam importantes aos outros, se depara com concorrentes cada vez mais 
preparados em produzir os mesmos produtos. Da mesma forma, seus pares também estão cada vez mais munidos de instrumentos para criticálo e colocar suas descobertas à prova. Sendo assim, os dominantes são também os mais competentes, os que "conseguem impor uma definição de ciência segundo a qual a realização mais perfeita consiste em ter, ser e fazer aquilo que eles têm, são e fazem" (BOURDIEU, 1983, p. 128).

Assim sendo, as publicações científicas podem ser consideradas como o principal meio pelo qual os pesquisadores se destacam academicamente, ou seja, se tornam visíveis à comunidade acadêmica. A partir dessas publicações, é que os cientistas recebem incentivos como bolsas e outros auxílios financeiros, evidenciando "o interesse do governo e de várias instituições de fomento à pesquisa no desenvolvimento científico" (PETROIANU, 2002, p. 60). Pode-se considerar, assim, o destaque profissional como um dos principais incentivos à publicação científica. Além disso, vale apontar que o egocentrismo, o incentivo financeiro e o reconhecimento perante a sociedade são fatores que em muito influenciam a produção científica, encorajando o pesquisador a publicar mais. De acordo com Petroianu (2002, p. 60), na carreira acadêmica, "a vaidade representada pelo amor à fama é um dos fatores que mais impulsionam o processo intelectual".

Percebe-se que a autoria tem elevada importância no ambiente acadêmico. Foucault (2006) afirma que, na Idade Média, os textos científicos só eram considerados verdadeiros se fossem marcados pelo nome do seu autor. "'Hipócrates disse', 'Plínio conta' não eram precisamente as fórmulas de um argumento de autoridade; eram os índices com que estavam marcados os discursos destinados a serem aceitos como provados". Conforme observado por Antonio (1998), essa situação se modificou durante os séculos XVII e XVIII, quando os trabalhos científicos começaram a receber reconhecimento de seus pares com a condição de serem resultado de "verdades já estabelecidas e sistematicamente demonstradas, ou ainda, quando se inseriam em sistemas teóricos e metodológicos organizados." (FOUCAULT, 2006, p. 275). Na ciência, o texto já é produto do trabalho de equipe de pesquisa, "no qual a autoria e as citações têm a função de permitir que seja traçada a genealogia do próprio texto e de seus autores, ou seja, permitem a verificação e a validação dos métodos empregados e dos resultados alcançados" (ANTONIO, 1998, p. 190).

Dessa forma, a indicação do autor representa mais do que a origem de um trabalho, mais do que a ideia de propriedade, ela confere credibilidade em relação às técnicas e experiências utilizadas. Além disso, Antonio (1998, p. 189) lembra que o nome do autor garante certo status ao trabalho, concedendo-Ihe "autenticidade (o discurso é real, verdadeiro), distinção (o discurso tem valor, é especial, importante) e permanência (o discurso conserva-se, fixa-se para a eternidade)". Outro aspecto relacionado à autoria é a função classificatória, possibilitando reagrupar uma determinada quantidade de textos, delimitá-los, selecionálos ao excluir alguns e opô-los a outros textos (FOUCAULT, 2006, p. 272). 
A popularização de tecnologias de informação e comunicação, em especial a Internet, viabilizou o surgimento de mudanças significativas na questão da autoria, nos processos de produção e disseminação científica e na repercussão da visibilidade dos cientistas, proporcionada pelo mundo conectado em redes, temas a serem tratados a seguir.

\section{A Internet e a produção científica}

O ambiente virtual permite que cada indivíduo realize várias funções ao mesmo tempo, podendo atuar como autor, produtor, editor, leitor e/ou consumidor, dependendo do seu objetivo naquele momento (ANTONIO, 1998).

Em especial, a Internet possibilita novas configurações de autoria. Observa-se, assim, uma alteração na função classificatória da autoria, uma vez que, na Internet, as obras não mais se apresentam unicamente como produções exclusivas de um autor que se pode reconhecer, "mas também como obra coletiva, múltipla e, frequentemente, anônima, fragmentada, incompleta, mutante e, muitas vezes, fugaz" (ANTONIO, 1998, p. 190). Nesse sentido, percebe-se que a rede de comunicações que se forma com o auxílio da Internet proporciona uma maior interação entre os indivíduos, permitindo que a criação, publicação, distribuição e uso das produções científicas aconteçam de forma integrada, simultânea e independente de espaço físico, aproximando, assim, autores, produtores e consumidores, ampliando as possibilidades de produção científica.

De acordo com Serra (2002, p. 1), a Internet foi entendida por muitos como sendo um espaço que permitiria "assegurar a universalidade e a igualdade em termos de visibilidade", ou seja, partiu de uma ideia utópica de que a Internet proporcionaria uma visibilidade universal e igualitária. De fato, essa rede não possui nenhum filtro ou autoridade reguladora que impeça qualquer pessoa, a qualquer momento, em qualquer local, de publicar o conteúdo que bem entender. Todavia, depositar esses conteúdos na rede não significa necessariamente ser visto ou ouvido.

Aliás, ser visto na Internet é tarefa cada vez mais árdua. Isso ocorre por conta de uma junção de dois fatores principais: a quantidade enorme e descontrolada de informações que são depositadas na rede a todo momento; e os métodos de busca utilizados para encontrar o que se deseja nesse emaranhado de conteúdos. Serra (2002) apresenta três formas de pesquisar a informação da Internet. A primeira é a consulta direta a um sítio específico, quando conhecemos o seu endereço URL previamente. A segunda forma, ao contrário da primeira, é a navegação sem destino definido, por meio, principalmente, das ligações hipertextuais. E a terceira forma de busca seria a utilização de motores de busca, valendo-se de palavras-chave ou de expressões específicas. Essa última, em especial, apresenta um problema particular: selecionar os sítios relevantes em meio à imensa quantidade de resultados obtidos na pesquisa. Obviamente existe a possibilidade de restringir a pesquisa e, assim, diminuir a quantidade de respostas; porém, essa restrição abriga o 
risco de excluir resultados que poderiam ser igualmente ou até mais relevantes do que aqueles que foram obtidos. Além desse problema, Serra (2002) afirma que os motores de busca apresentam outras dificuldades, tais como:

a)relatividade dos critérios de relevância em cada motor de busca: um mesmo documento pode ser considerado muito relevante para um motor de busca e pouco relevante para outro;

b)dificuldade em estabelecer, de forma precisa e objetiva, relações semânticas entre os termos; além da ocorrência de homonímias; e

c)problemas na adoção dos critérios utilizados para medir a popularidade e a autoridade. Primeiro porque as páginas mais recentes não podem, de imediato, terem sido muito citadas, e, por isso, não são classificadas como "populares", tornando essas páginas "invisíveis", como se não tivessem nenhum mérito. $E$, por último, há de se compreender que o mais popular, o mais visto e citado não é, necessariamente, o mais relevante.

Portanto, o que se observa é que os motores de busca, de fato, têm uma importantíssima contribuição na difícil missão de encontrar a informação desejada em meio ao crescimento desenfreado de conteúdo que é disponibilizado na Internet. Todavia, mesmo com toda a evolução tecnológica, o bom senso humano ainda é indispensável: é preciso verificar as fontes e avaliar as informações encontradas antes de consumilas e utilizá-las.

Além disso, os problemas citados acima, referentes aos motores de busca na Internet, nos remetem à questão anterior, da visibilidade. O fato de que qualquer indivíduo possa, a princípio, a qualquer momento, criar a página que desejar e incluir o conteúdo que bem entender, não significa que a Internet seja exatamente um lugar de igualdade, que permite visibilidade a todos os produtores de conteúdo. Tornar um conteúdo amplamente visível, ao menos em termos científicos, exige outros requisitos, tais como a qualidade da informação. O que se percebe é que interesses econômicos, sociais e ideológicos fazem com que a rede aumente a cada minuto. Todavia, o que motiva esse crescimento, em grande parte, é a busca por notoriedade, por visibilidade. Quem disponibiliza conteúdos na Internet, o faz com o intuito de atrair a atenção de um maior número possível de espectadores e, para tal, se esforça para que o seu conteúdo chame mais atenção do que os outros milhões de conteúdos disponíveis na rede. Sendo assim, a Internet, atualmente, se configura muito mais como uma rede de concorrência, por visibilidade, do que uma rede igualitária (FIDALGO, 2001). 
A Internet, do ponto de vista de uma rede igualitária, como dito acima, facilita imensamente a disponibilização de conteúdos, por quem quer que seja. Todavia, neste cenário existem dois fatores que devem ser analisados. O primeiro é que toda essa informação disponível precisa ser avaliada antes de ser utilizada, pois, uma vez que não existe nenhum filtro ou órgão que regule o que pode ou não ser disponibilizado na rede, é preciso verificar a fonte e a veracidade das mesmas. O segundo fator é que, ao mesmo tempo em que cresce o número de produtores de conteúdo, também cresce o número de espectadores, os quais, por vezes, cumprem a função de avaliadores daqueles conteúdos. Ou seja, ao mesmo tempo em que existem milhões e milhões de pessoas depositando seus trabalhos na rede, existem outras milhões e milhões de pessoas vigiando esses trabalhos, avaliando a qualidade deles, julgando os melhores e, assim, aumentando a visibilidade dos mesmos.

Portanto, a comunicação científica é o meio pelo qual os autores, além de comunicarem suas descobertas, colocam os seus trabalhos à disposição para a avaliação de seus pares, os quais decidirão por qualificálas ou não. Essa qualificação é uma forma de reconhecimento do trabalho do pesquisador e, como consequência, faz com que ele seja visto pela comunidade acadêmica.

Em meio à quantidade exorbitante de informações existentes, conseguir aumentar a sua visibilidade e de suas pesquisas é imprescindível ao cientista, pois é assim que conseguirá se destacar e ter seu trabalho reconhecido. A Internet, no papel de facilitadora desse processo, desempenha função primordial, uma vez que é uma das tecnologias que mais contribui para a comunicação científica.

Para avaliar o impacto da produção acadêmica de um autor, mensurar o interesse gerado por esta e o reconhecimento da mesma na comunidade científica, existem instrumentos desenvolvidos para essa finalidade, sendo que alguns serão detalhados a seguir.

\section{Medidas de impacto da produção científica}

A avaliação da qualidade acadêmica de um cientista é possibilitada por meio de sua produção científica. Os resultados de pesquisa científica representam a contribuição de um pesquisador, que é utilizada para estimar a sua autoridade, crédito e valor e como medida para avaliar o seu reconhecimento ou sua reputação junto à comunidade científica (MUGNAINI, 2006).

A pesquisa científica é insumo básico para o progresso mundial e, por isso, governo e instituições disponibilizam importante e considerável apoio financeiro à realização dessas pesquisas. Tais financiamentos são cada vez mais concorridos entre os pesquisadores; sem contar o fato de que os investidores procuram saber se os seus investimentos estão sendo bem aplicados. Dessa forma, as agências de fomento avaliam a qualidade da pesquisa que financiam com o objetivo de embasar suas decisões acerca de investimentos futuros (ADLER; EWING; TAYLOR, 2009 apud CORTELLI, 2010) e existem várias iniciativas para mensurar o quanto uma 
publicação impacta outras publicações. Nessa perspectiva, em tese, quanto mais impacto cause uma publicação científica maior é a sua qualidade como contribuição científica.

Com o intuito de avaliar a excelência acadêmica de um pesquisador, utilizou-se como parâmetro, durante muito tempo, a quantidade de pesquisas publicadas. Todavia, existe um consenso em afirmar que esses parâmetros devem contemplar, ainda, a qualidade dessas publicações (STREHL, 2005). Meadows (1999, p. 89) aponta que uma forma de avaliar essa qualidade é "verificar o nível de interesse dos outros pela pesquisa". Para se conseguir essa medida utiliza-se a análise de citações, a qual mede a quantidade de citações que uma pesquisa recebeu em pesquisas subsequentes.

A análise de citações é um dos diversos tipos de indicadores bibliométricos existentes. Os indicadores bibliométricos têm sido usados na avaliação da produção científica e são gerados a partir de "artigos científicos publicados em periódicos considerados de qualidade internacional e que refletem a produção científica de uma determinada comunidade" (PINTO et al., 2010, p. 201). Esses indicadores são as principais ferramentas da bibliometria e da cienciometria. Pacheco e Kern (2001, p. 57) definem a bibliometria como sendo o campo que estuda quantitativamente a "produção, disseminação e circulação (empréstimos) de documentos científicos, incluindo autores e usuários". Já a cienciometria tem o objetivo de detectar "domínios de interesse (áreas, assuntos, disciplinas) e compreender a comunicação entre cientistas", e, para tal, analisa quantitativamente as atividades científicas. De acordo com Umbelino (2008, p. 96), "os indicadores bibliométricos aplicam-se fundamentalmente a artigos científicos por considerar que esses são a manifestação mais elaborada de um investigador" de modo que possibilitam o seu reconhecimento profissional. Em relação à cienciometria, Pinto e Andrade (1999) afirmam que esse indicador é um dos principais responsáveis pela existência de tantas informações quantitativas sobre a ciência e também de comparações sobre o desempenho científico de países, comunidades científicas ou instituições.

Geralmente os índices bibliométricos são obtidos a partir de bancos de dados, nos quais são catalogadas uma parte significativa da literatura científica mundial produzida todos os anos. O principal banco de dados utilizado para essa finalidade é o criado pelo Institute for Scientific Information (ISI) (PINTO; ANDRADE, 1999). Na década de 1960, este instituto criou o Journal Citation Reports (JCR), com o intuito de fornecer dados quantitativos que subsidiem a avaliação dos periódicos, informando a quantidade de vezes que os artigos de uma determinada revista são citados nos periódicos científicos indexados na base de dados do ISI (CORTELLI, 2010). O JCR publica, anualmente, três indicadores para cada título de periódico: o índice de citação imediata (immediacy index), a meia-vida das citações (cited half-life) e, o mais utilizado deles, o Fator de Impacto (impact factor - FI) (STREHL, 2005). 


\subsection{Fator de impacto}

Corroborando o que foi exposto anteriormente, Mugnaini e Población (2007, p. 2) afirmam que o impacto científico, o qual geralmente está associado à qualidade da investigação, "é atribuído a um documento publicado, quando citado posteriormente em outras publicações". Nesse sentido, as bases de dados se transformaram na principal fonte de informação para medir o impacto, o qual, por sua vez, é atribuído ao autor e à instituição em que foi gerado, permitindo as mais diferentes análises e colaborando para as comparações dos desempenhos acadêmicos.

Assim, os dados de citações e os índices bibliométricos passaram a ser utilizados como parâmetro de avaliação de cientistas e instituições. 0 fator de impacto (FI), por sua vez, apresenta-se como um importante instrumento de avaliação da influência que um determinado periódico exerce na comunidade científica. De acordo com Umbelino (2008), uma publicação é avaliada em decorrência do número de vezes em que foi citada por outros artigos. Logo, quanto maior o número de obras que referenciam um trabalho que foi publicado em um dado periódico, maior será o seu fator de impacto. Dessa forma, o FI auxilia na avaliação da importância relativa de um periódico cientifico quando comparado a outros periódicos constituintes do mesmo campo científico, tornando-se, assim, o indicador bibliométrico mais comumente utilizado. Além disso, conforme lembrado por Cortelli (2010), o FI também auxilia os editores de revistas a selecionar ou descartar certos títulos de suas coleções; enquanto que aos autores é possível identificar os periódicos mais influentes e adequados para publicar suas pesquisas.

Complementando essa ideia, Strehl (2005) defende a importância do FI na difusão do conhecimento científico em virtude da influência que exerce no cotidiano de autores, bibliotecários, editores e gestores da ciência. No caso dos autores, o FI auxilia na identificação dos periódicos mais adequados para submeterem suas pesquisas, uma vez que o FI indica as revistas que podem gerar maior prestígio aos seus trabalhos. Já os bibliotecários se baseiam nesse indicador para selecionar os títulos de periódicos a serem adquiridos, considerando o interesse dos cientistas e, assim, otimizando os recursos orçamentários muitas vezes escassos. Os editores de periódicos, por sua vez, acompanham a evolução dessas medidas de impacto, de modo a adequarem suas publicações tornando-as atrativas aos autores para que consigam publicar os artigos mais importantes e, assim, captar os recursos das bibliotecas. Por fim, as agências de fomento se valem do FI para avaliar os pesquisadores, fato esse que, consequentemente, realimenta a necessidade de uso do FI por parte dos autores, bibliotecários e editores (STREHL, 2005).

Para calcular o FI de um periódico divide-se o número de citações recebidas no período de dois anos pelo número de todos os artigos publicados nesse periódico durante esse mesmo período. É importante ressaltar que somente os periódicos indexados no ISI são considerados nesse cálculo. O ingresso de um periódico nessa base de dados exige muitos requisitos, tais como pontualidade de publicação (respeito à 
periodicidade estabelecida) e cumprimento das normas internacionais editoriais (presença de título informativo, resumo, descritores, fidelidade das referências citadas, etc.). Os critérios de seleção são rigorosos por conta do compromisso do ISI de "oferecer cobertura completa dos periódicos mais importantes e influentes do mundo para atualização de informações" e por acreditar que a cobertura completa deve priorizar a qualidade e não a quantidade (GARFIELD, 1995 apud UMBELINO, 2008, p. 97).

O FI de periódicos indexados no ISI são publicados no JRC desde 1972. Essa publicação reúne os dados no Science Citation Index (SCI), Social Sciences Citation Index (SSCI) e Arts and Humanities Citation Index (AHCI). Até muito recentemente, somente os dados gerados a partir das bases de dados do ISI, principalmente o SCI e o SSCI, tinham condição de disponibilizar dados de impacto dos periódicos dentro da comunidade científica. Mugnaini e Strehl (2008) afirmam que esse domínio ocorreu também em países com uma quantidade irrisória de periódicos contemplados em bases de dados internacionais. Todavia, com o surgimento de outras bases de dados indexadoras de citações, ocorreram mudanças nessa situação, uma vez que as novas bases de dados estão disputando espaço no campo de produção de informações para a mensuração do impacto das publicações científicas, espaço até então ocupado pelo ISI. Entre essas bases, conforme Mugnaini e Strehl (2008), estão o Scientific Eletronic Library Online (SciELO), modelo que conta com um sistema para medição do fator de impacto das revistas, nos mesmo moldes do ISI (FERREIRA, 2010); Scopus, base de dados com uma cobertura maior de publicações; e Google Acadêmico, uma versão do Google para buscas de documentos científicos.

Assim que o $\mathrm{FI}$ se consagrou como um índice bibliométrico internacionalmente utilizado, começaram a surgir diversas pesquisas sobre esse assunto. Como resultado observou-se que existem fatores que em muito influenciam esse indicador, podendo resultar em interpretações errôneas de seus valores. Inicialmente constatou-se que para as diferentes áreas do conhecimento os valores do FI sofrem muitas variações. Strehl (2005, p. 21) expõe que "com a difusão do uso do FI, verificou-se que os valores do indicador que caracterizam as várias áreas do conhecimento diferem grandemente". Umbelino (2008) corrobora essa afirmação ao declarar que não se pode fazer comparações entre as áreas temáticas, considerando que os hábitos de publicação e de produtividade dos autores se distinguem em cada área.

De acordo com Mugnaini e Strehl (2008) e Strehl (2005), o ritmo de obsolescência da literatura e a densidade dos artigos são os fatores que mais afetam os resultados do FI. Em relação à obsolescência, é preciso lembrar que cada área do conhecimento apresenta o seu ritmo de evolução e morte dos seus conteúdos. Assim, "o tempo de pertinência dos conhecimentos produzidos varia de acordo com o ritmo de atualização de cada um dos diversos ramos do saber, apresentando invariavelmente reflexo na idade das referências citadas nas publicações" (STREHL, 2005). Umbelino (2008) concorda com isso ao afirmar que as áreas que crescem 
mais rapidamente tendem a citar trabalhos mais recentes, enquanto que as áreas de crescimento menos intenso preferem citar trabalhos mais antigos. Considerando que o cálculo do FI de um periódico leva em conta somente as citações feitas aos artigos publicados nos últimos dois anos, as áreas que apresentam uma taxa elevada de trabalhos não citados nos primeiros anos após a sua publicação, ou seja, que tem baixa obsolescência, terão um impacto consideravelmente menor se comparadas às disciplinas em que as publicações geralmente são citadas assim que publicadas.

Ainda de acordo com Umbelino (2008), o avanço das pesquisas sobre FI permitiu observar que esse indicador favorece as áreas que possuem um número maior de cientistas, uma vez que quanto mais cientistas, maior o número de publicações e, assim, maior a possibilidade de ser citado. Além disso, Umbelino (2008) explica que existem outros fatores podem influenciar o FI, tais como:

a)quantidade de periódicos por área: quanto maior a quantidade de revistas, maior a probabilidade dos artigos dessa área serem citados;

b)tamanho dos periódicos: quanto mais artigos contém uma determinada revista, menor pode ser o seu FI, haja vista que a quantidade de artigos publicados pela revista faz parte do cálculo do FI; e

c)tipo do periódico: artigos de revisão, por exemplo, recebem uma quantidade elevada de citações por um período mais demorado. Logo, revistas que publicam esse tipo de artigo tendem a ter o seu FI aumentado.

Seguindo essa mesma linha de pensamento, Mugnaini e Población (2007) apresentaram um estudo apontando diversas inconsistências presentes nas fontes utilizadas para calcular os indicadores. Entre eles destacam-se:

a)quantidade de citações recebidas: existem diversas razões para citar um documento, inclusive criticar ou contestar o resultado de uma pesquisa. Sendo assim, citação não é, necessariamente, indicação de qualidade da pesquisa;

b)bases de dados: o escopo de uma base de dados exerce influência sobre a quantidade de citações recebidas, haja vista que se destina ao um público específico com características específicas e com documentos que diferem em tipo, área do conhecimento, idade, etc.;

c)revistas: cada revista tem sua particularidade, diferindo na quantidade de artigos publicados em certo período e também na forma de seleção desses artigos; e 
d)artigos publicados: os resultados de cada pesquisa podem variar de acordo com as metodologias adotadas nas etapas de investigação.

Café e Bräscher (2008, p. 56) apontam, ainda, que a correta "descrição física e de conteúdo é essencial para os estudos bibliométricos", assim como para a recuperação da informação. Isso porque a descrição, enquanto "identificação única de um item de informação", é imprescindível à realização de análises bibliométricas, uma vez que "os pesquisadores que desenvolvem estudos bibliométricos também necessitam de um conjunto de descrições padronizadas para constituir seu corpus de pesquisa e realizar suas análises".

A junção desses diversos vieses pode anular um indicador bibliométrico, visto que permite compreender que esse indicador não oferece dados fidedignos ao fator que está sendo analisado. Nesse sentido, é preciso estar atento a esses fatores de modo a garantir que os estudos bibliométricos ofereçam resultados consistentes.

Quanto à densidade de uma publicação, definida por Garfield (1999) como o número médio de referências citadas nos artigos de um determinado periódico; Strehl (2005) defende que determinadas áreas do conhecimento citam mais ou menos referências por cada artigo publicado. Além disso, o número de citações recebidas por um artigo varia proporcionalmente de acordo com a sua densidade. Ou seja, disciplinas que costumam citar poucas referências em seus artigos recebem, em média, poucas citações e vice-versa.

A partir das informações apresentadas, observa-se que existem muitas variáveis que podem afetar os valores do FI. Portanto, ao se utilizar o FI como critério para avaliar a produção científica, é indispensável levar em conta a existência e influência dessas variáveis, de modo a evitar que diferenças entre os padrões de citações entre as diversas áreas do conhecimento sejam interpretadas como diferenças específicas de qualidade entre os artigos (MUGNAINI; STREHL, 2008).

Ainda que o FI seja proveniente de um contexto bastante complexo, ele continua a ser amplamente adotado. Segundo Glänzel e Moed (2002), isso se deve ao fato de ser um indicador facilmente compreensível; robusto, pois não sofre muitas variações de um ano para o outro; e de rápida disponibilidade, se considerarmos a agilidade do ISI quanto à sua indexação e distribuição. Entretanto, mesmo sendo o indicador bibliométrico mais conhecido, existem outros indicadores importantes, como veremos a seguir.

\section{2 Índice de citação imediata e meia vida das citações}

O índice de citação imediata mede o quão rapidamente os artigos de um periódico são citados a partir da sua data de publicação. Para calcular esse índice, basta dividir a quantidade de citações recebidas por um periódico em um determinado ano pelo número de artigos que foram publicados nesse mesmo ano (AMIN; MABE, 2000). Strehl (2005, p. 22) 
explica que esse "índice representa a rapidez com que um trabalho é citado, sendo que, quanto menor o tempo transcorrido da publicação de um documento e sua citação em outros, maior será o seu valor".

Para calcular a obsolescência da literatura é usado o índice de meiavida das citações. Strehl (2005, p. 23) esclarece que o "termo meia-vida das citações teve origem no conceito físico de meia-vida dos materiais radioativos". Burton e Kleber, em 1960, segundo essa autora, passaram a usar o termo para expressar o período em que uma pesquisa alcança a metade de sua vida útil. Sendo assim, a meia-vida das citações mede o tempo em que um artigo continua a ser citado após a sua publicação. De acordo com o JCR (1998 apud STREHL, 2005), esse indicador representa o tempo, em anos, que é preciso decorrer para que $50 \%$ das citações recebidas por um dado periódico apareçam na literatura. Com esses dados é possível avaliar não apenas a obsolescência, mas também o nível de influência de um periódico. Meadows (1999, p. 97) alerta que "uma característica marcante de publicações importantes é não só o fato de serem altamente citadas, mas serem citadas durante um período de tempo mais longo do que outras publicações".

\section{3 Índice $h$}

$\mathrm{O}$ índice $\mathrm{h}$ (do inglês $h$-index) é um indicador mais recente, foi desenvolvido em 2005 por Jorge Hirsch, um pesquisador argentino da Universidade da Califórnia. Tal índice tem por objetivo mensurar a produtividade científica de um pesquisador ao longo de sua carreira. Para isso, verifica a quantidade de artigos que receberam um número de citações maiores ou iguais a essa quantidade. Ou seja, um pesquisador que tenha um índice $\mathrm{h}=15$ publicou, pelo menos, 15 artigos que receberam, no mínimo, 15 citações em outras pesquisas. Esse índice é encontrado em bases de dados como o Google Acadêmico, Web of Science e Scopus. Assim como o FI, a adoção do índice h também apresenta algumas ressalvas. De fato, 0 índice $h$ auxilia na avaliação da produtividade de um autor, todavia, não pode ser utilizado para medir o real impacto das publicações cientificas ou mesmo a quantidade de citações recebidas pelo autor avaliado (CORTELLI, 2010).

O que se observa com a análise de todos esses indicadores bibliométricos é que avaliar a produção cientifica é uma tarefa muito complexa e ainda não existe uma medida simples e objetiva para embasar essa avaliação. Muitos estudos são realizados nessa área e já ocorreram muitos avanços, mas é preciso ter consciência de que os instrumentos existentes ainda são bastante limitados e, por isso, devem ser utilizados com cautela. O ideal seria ter mente que na análise de indicadores quantitativos devem ser incorporadas outras variáveis (área do conhecimento, país, etc.) para que a avaliação realizada seja mais representativa da realidade.

\section{Considerações finais}


Enfim, aqui tratamos de uma pequena parte de um complexo sistema de produção científica. Na sociedade contemporânea, os pesquisadores têm muitas atribuições e obrigações. Como seres sociais, são movidos pelos seus anseios, suas vaidades, seus desejos, suas idiossincrasias e são influenciados pelo contexto de produção científica e, muitas vezes, são quase reféns de investimentos e de recursos disponíveis. Além disso, é preciso lembrar que quando falamos de sistema de produção científica não devemos esquecer a importância das bibliotecas, das bases de dados, dos editores de revistas, dos comitês editoriais e avaliadores, das editoras e das sociedades científicas, ou seja, de pessoas e instituições que garantem a existência de todo esse intrincado sistema.

Cabe frisar que reconhecemos que passamos por um processo de mudanças no modo de produção científica e nos meios de disseminação científica e que estamos vivenciando um momento no qual valores ligados a uma cultura empresarial têm influenciado, sobremaneira, esses processos. Todavia, parece precoce fazer uma avaliação positiva ou negativa dos efeitos de tais transformações, afinal, como lembra Gleiser (2004, p.3), "a ciência é uma narrativa em constante evolução", portanto, resta-nos aguardar pelo desenrolar dos próximos atos.

\section{Referências}

ADLER; EWING; TAYLOR, 009 apud CORTELLI, 2010

AMIN, M.; MABE, M. Impact factor: use and abuse. Perspectives and Publishing, n. 1, p. 1-6, 2000. Disponível em: <http://www3.ntu.edu.sg/home/MWTANG/ifuse.pdf>. Acesso em: 23 nov. 2011.

ANTONIO, I. Autoria e cultura na pós-modernidade. Ciência da Informação, Brasília, v. 27, n. 2, p. 189-192, maio/ago. 1998.

BOURDIEU, P. O campo científico. In: ORTIZ, R. (Org.). Pierre Bourdieu: sociologia. São Paulo: Ática. 1983. p.122-155.

CAFÉ, L.; BRASCHER, M. Organização da informação e bibliometria. Encontros Bibli: Revista Eletrônica de Biblioteconomia e Ciência da Informação, Florianópolis, $\mathrm{n}$. esp., $1^{0}$ sem. 2008. Disponível em: <http://redalyc.uaemex.mx/redalyc/pdf/147/14709806.pdf. >.

Acesso em: 20 dez. 2011.

CORTELLI, J. R. O desafio de se classificar revistas científicas e pesquisadores: fator de impacto das revistas científicas. Revista Periodontia, v. 20, n. 4, p. 7-10, dez. 2010. Disponível em: <http://www.revistasobrape.com.br/arquivos/dez2010/artigo1.pdf>. Acesso em: 23 nov. 2011.

DEUS, J. D. (Org.). A crítica da ciência: sociologia e ideologia da ciência. 2. ed. Rio de Janeiro: Zahar, 1979. 
FIDALGO, A. Metáfora e realidade ou cooperação e concorrência na rede. Universidade da Beira Interior, 2001. Disponível em: <http://www.bocc.ubi.pt/pag/ fidalgo-antonio-rede-metaforarealidade.pdf >. Acesso em: 26 out. 2011.

FIGUEIREDO, N. M. de. Serviços de referência \& informação. São Paulo: Polis, 1992.

FOUCAULT, M. O que é um autor? In: DITOS e escritos III: estética: literatura e pintura, música e cinema. Rio de Janeiro: Forense Universitária, 2006. p. 264-298.

GARFIELD, E. Journal impact factor: a brief review. Canadian Medical Association Journal, v. 161, n. 8, p. 979-980, october 1999. Disponível em: <http://www.cma.ca/ cmaj/vol-161/issues-8/0979.htm>. Acesso em: 23 nov. 2011.

GARFIELD, 1995 apud UMBELINO, 2008

GARGOURI, Yassine; HARNAD, Stevan; HAJJEM, Chawki. Impact of openaccess self-archiving mandate on citation advantage. 2009. Disponível: $<$ http://users.ecs.soton.ac.uk/harnad/ Temp/selfarchdraft1.doc $>$. Acesso em: 20 dez. 2011.

GLÄNZEL, W.; MOED, H. F. Journal impact measures in bibliometric research. Scientometrics, v. 53, n. 2, p. 171-193, 2002. Disponível em: <http://www.springerlink.com/ content/0prnbd5xax cwf7gt/ fulltext.pdf>. Acesso em: 23 nov. 2011.

GLEISER, M. Um amante da ciência. Jornal da UNESP, São Paulo, n. 94, p.1-15, nov.2004.

HAGSTROM, W. O. O controle social dos cientistas. In: DEUS, J. D. (Org.). A crítica da ciência: sociologia e ideologia da ciência. 2. ed. Rio de Janeiro: Zahar, 1979.

JCR (1998 apud STREHL, 2005

LATOUR, B.; WOOLGAR, S. A vida do laboratório: a produção dos fatos científicos. Rio de Janeiro: Relume Dumará,1997.

LAWRENCE, Steve. Online or invisible? Nature, v. 411 , n. 6837, p. 521, 2001. Disponível em: <http://www.nature.com/nature/journal/ v411/n6837/pdf/411521a0.pdf>. Acesso em: 27 out. 2011.

LE COADIC, Y.-F. A ciência da informação. 2. ed. Brasília: Briquet de Lemos, 2004.

MEADOWS, A. J. A comunicação científica. Brasília: Briquet de Lemos, 1999.

MERTON, R. K. Os imperativos institucionais da ciência. In: DEUS, J. D. (Org.). A crítica da ciência: sociologia e ideologia da ciência. 2. ed. Rio de Janeiro: Zahar, 1979. p. 37-52. 
MUGNAINI, R. Caminhos para adequação da avaliação da produção científica brasileira: impacto nacional versus internacional. São Paulo, 2006. 253f. Tese (Doutorado em Ciência da Informação) - Escola de Comunicações e Artes, Universidade de São Paulo, 2006. Disponível em: <http://poseca.incubadora.fapesp.br/portal/ bdtd/ 2006/2006-domugnaini_rogerio.pdf.>. Acesso em: 23 nov. 2011.

MUGNAINI, R.; POBLACIÓN, D. A. de M. A. Impacto de documentos citados em revistas científicas brasileiras de diferentes áreas. In: ENCONTRO NACIONAL DE PESQUISA EM CIÊNCIA DA INFORMAÇÃO, 8., 2007, Salvador. Anais eletrônicos... Salvador: UFBA, 2007. Disponível em: <http://www.enancib.ppgci.ufba.br/artigos/GT7--228.pdf>. Acesso em: 23 nov. 2011.

MUGNAINI, R.; STREHL, L. Recuperação e impacto da produção científica na era google: uma análise comparativa entre o Google Acadêmico e a Web of Science. Encontros Bibli: Revista Eletrônica de Biblioteconomia e Ciência da Informação, Florianópolis, n. Especial, p. 92-105, $1^{\circ} \mathrm{sem}$. 2008. Disponível em: <http://www.periodicos.ufsc.br/index.php/eb/ article/view/1518-2924.2008v13nesp1p92>. Acesso em: 23 nov. 2011.

OLIVEIRA, E. B.; NORONHA, D. P. A comunicação científica e o meio digital. Informação e Sociedade, João Pessoa, v. 15, p. 1-12, 2005. Disponível em: <http://www.informacaoesociedade. ufpb.br/ html/IS1510503/>. Acesso em: 15 set. 2011.

PACHECO, R. C. dos S.; KERN, V. M. Uma ontologia comum para a integração de bases de informações e conhecimento sobre ciência e tecnologia. Ciência da Informação, Brasília, v. 30, n. 3, dez. 2001.

PETROIANU, A. Autoria de um trabalho científico. Revista da Associação Médica Brasileira, São Paulo, v. 48, n. 1, p. 60-65, 2002. Disponível em: <http://www.scielo.br/ pdf/ramb/v48n1/a31v48n1.pdf>. Acesso em: 26 out. 2011.

PINTO, A. L.; IGAMI, M. P. Z.; BRESSIANI, José Carlos. Visibilidade e monitoramento científico na área nuclear e ciências relacionadas: uma perspectiva a partir da produtividade do IPEN-CNEN/SP. Perspectivas em Ciência da Informação, Belo Horizonte, v.15, n.2, p. 198-218, maio/ago. 2010. Disponível em: <http://portaldeperiodicos. eci.ufmg.br /index.php/pci/article/view/1033/795>. Acesso em: 23 nov. 2011.

PINTO, A. da C.; ANDRADE, J. B. de. Fator de impacto de revistas científicas: qual o significado deste parâmetro? Revista Química Nova, v. 22, n. 3, p. 448-453, 1999. Disponível em: <http://www.scielo.br/pdf/qn/v22n3/1101.pdf>. Acesso em: 23 nov. 2011.

SERRA, J. P. A internet e o mito da visibilidade universal. Universidade da Beira Interior, 2002. Disponível em: <http://www.bocc. ubi.pt /pag/serrapaulo-internet-mito-visibilidade-universal.pdf>. Acesso em: 26 out. 2011. 
STREHL, L. O fator de impacto do ISI e a avaliação da produção científica: aspectos conceituais e metodológicos. Ciência da Informação, Brasília, v. 34, n. 1, p. 19-27, jan./abr. 2005.

UMBELINO, F. M. B. C. Factor de impacto de revistas científicas na área de enfermagem. Revista Referência, v. 2, n. 8, p. 95-100, 2008. Disponível em: $\quad<$ http://www.esenfc.pt /rr/rr/ index.php?pesquisa $=$ dor\&id_website $=3 \&$ target=DetalhesArtigo \&id _artigo $=2126>$. Acesso em: 23 nov. 2011.

ZIMAN, J. A força do conhecimento: a dimensão científica da sociedade. São Paulo: USP, 1981.

ZIMAN, J. O conhecimento confiável: uma exploração dos fundamentos para a crença na ciência. Campinas: Papirus, 1996. 